\title{
THE PROVISION OF HOSPITALS FOR SMALL-POX.*
}

BY EDWARD SERGEANT, L.R.C.P., M.R.C.S., L.S.Sc,

Medical Officer of Health for Lancashire.

The appearance of small-pox in this county from time to time, and the extension of the disease which not infrequently takes place owing to the difficulty of securing efficient isolation for the persons attacked, renders it desirable in the interests of the public that hospital accommodation should be available in case of epidemic invasion. In order more effectually to curtail the spread of a disease like small-pox, it is of the first importance to have a hospital always in readiness for the admission of patients, and not depend on buildings hastily provided or adapted during the stress of an epidemic. Again, small-pox is a disease which must be dealt with on a site separate from other diseases, for experience has shown that it has a greater power of distribution than ordinary infectious diseases, and the presence of the disease within half a mile of a populous community is a source of danger. It has been found that even when treated in a special pavilion of an isolation hospital small-pox has been introduced among the other patients, and great difficulties have in consequence arisen. In a recent memorandum the Local Government Board, with a view of lessening the risk of infection from small-pox, require the following conditions :

"1. The site must not have within a quarter of a mile of it either a hospital, whether for infectious diseases or not, or a workhouse, asylum, or any similar establishment, or a population of as many as 200 persons.

“2. The site must not have within half a mile of it a population of as many as 600 persons, whether in one or more institutions, or in dwelling-houses."

It is further required that even where the above conditions are fulfilled the hospital must not be used at one and the same time for the reception of cases of small-pox and of any other class of disease. Cases in which there is any considerable collection of inhabitants just beyond the half-mile zone should always call for special consideration; therefore, whatever combination is come to with respect to ordinary infectious diseases, there can be no doubt as to the desirability of authorities combining for small-pox

* From an address delivered at a preliminary conference of local anthorities at Wigan, July 9 th, 1902. 
purposes. In this way economy is secured, for each authority has to pay much less towards the initial structural charges, and there is a reduction in the annual ccst of maintenance, ete. Efficiency is also secured, for a larger number of beds will always be available for the wants of each district than could reasonably be provided individually. If, as may frequently occur, the hospital should remain empty for, say, twelve months or more, the establishment charges in the case of a large combined area would not be so great as compared with the security enjoyed.

In forming a small-pox hospital district, the size of the area and population have to be borne in mind. The larger the population within reasonable limits, the less proportionate number of beds will be required to be permanently provided, with, of course, a less expenditure incurred. Consideration must also be paid to state of efficiency or otherwise of vaccination. A small-pox hospital will also serve a wider area than one for other infectious diseases.

The hospital area now under consideration is comprised within a radius of ten miles, and it is not likely that any injury to a small-pox patient would be incurred by removal in a properlyconstructed ambulance carriage to a hospital centrally situated, say within twelve miles of any part of the proposed district.

The first difficulty with respect to a small-pox hospital is the site. This should be as extensive as possible, and suitably isolated, so that owners of surrounding property will be reasonably protected from danger attributable to such an establishment; and, further, the construction of the hospital should be on the best principles. In this way a small-pox hospital may become more expensive than one constructed for the treatment of ordinary infectious diseases. The next point to be considered is the number of beds wanted, and this will also decide the structural expenditure. I may say that the wants of the proposed district have received my careful consideration, and I do not think that the total number of beds permanently provided need exceed forty. The cost of such a hospital-exclusive of land, which varies in value-say in three pavilions (two large and one small, the latter for observation purposes), with administrative block and requisite outbuildings, including disinfecting and washing apparatus, ought not to exceed $\$ 20,000$, while the ordinary upkeep when not occupied with patients would amount to 4450 or $£ 500$ per annum. The total expenditure for these purposes, including repayment of capital in thirty years, with interest at the rate of $3 \frac{1}{4}$ per cent., would not, in my opinion, exceed $£ 1,600$ per annum, or less than $\frac{1}{2} \mathrm{~d}$. in the $\&$ on the assessable value of the whole of the district. In isolation hospital districts hitherto 
formed by the County Council, all expenses incurred by the hospital committee are elassified as "structural" expenses, "establishment" expenses, and "patients" expenses, as defined by Section 17 of the Isolation Hospitals Act, 1893. The structural and establishment expenses are paid out of a common fund, to which all receipts are carried, and to which the constituent authorities contribute pro rata, according to the number of inhabitants in their respective districts, as shown by the last census in force.

THE protective power of vaceination is limited only by the carelessness, ignorance, and prejudice which prevents universal vaccination.

The Administration of the Vacoination Acts. - The Cardiff Corporation has passed a resolution urging the desirability of transferring to sanitary authorities the administration of the Vaccination Acts and the abolition of Section 2 of the Vaccination Act, 1898, relating to the "conscientious objector." This decision was arrived at after the presentation of a report from the medical officer of health (Dr. Edward Walford), in which he stated that since the passing of the Act until the end of March, 1902, the number of exemption orders in Cardiff accorded the objectors had been 288 , equal to 1.8 per cent. of the births registered during the same period. With reference to the transfer of the administration of the Acts, Dr. Walford says: "In Cardiff I have every reason to believe that the Guardians have carried out the Acts in a conscientious manner, but the reasons which governed Parliament in placing vaccination under the guardians of the poor in the year 1840 no longer exist. Since that date the Public Health Act, 1875, has come into operation, placing matters connected with sanitation and the prevention of disease under the jurisdiction of urban and rural sanitary authorities. The most important measure connected with the prevention of small-pox still remains, however, in the hands of the Board of Guardians, although vaceination does not by any means only concern paupers. The responsibility of dealing with an outbreak of small-pox, and of preventing its spread by isolation and disinfection, devolves upon the sanitary authority, which has no means of knowing the localities in the district in which primary vaccination has been neglected-that is to say, the localities in which the disease is most likely to spread-except by means of information derived from the Guardians, or by undertaking work which properly belongs to the vaccination officer. Even so long ago as in 1854 the President of the Poor Law Board expressed his doubts in the House of Commons ' whether it was a wise course to place vaccination in connection with the poor laws in any way.' Practically all the proceedings under the Vaccination Acts form an important branch of public health work, and have no connection with the relief of the poor, and they would, I believe, be more conveniently administered by the authority responsible for the public health. Further, in the case of vaccination or revaccination of persons on board vessels infected with small-pox, it would tend to prevent delay if the port sanitary authority, whose officers are on the spot, were also the vaccination authority. Delay in such cases may mean interference with, and damage to, the trade of the port." 